\title{
Convergence, Creative Industries and Civil Society: Towards a New Agenda for Cultural Policy and Cultural Studies
}

\author{
By Colin Mercer
}

\begin{abstract}
In this article I start with a personal experience "cameo" from 1996 in Australia and extrapolate from that some issues that remain relevant in the sometimes troubled relationship between cultural studies and cultural policy. These are encapsulated in the three "cs" of convergence, creative industries and civil society which provide a new context for both new research and new policy settings. The argument is developed and situated in historical terms by examining the "cultural technologies", especially the newspaper, and subsequently print media in the $19^{\text {th }}$ century, electronic media in the $20^{\text {th }}$ century and digital media in the $21^{\text {st }}$ century which provide the content, the technologies and the rituals for "imagining" our sense of place and belonging. This is then linked to ways of understanding culture and cultural technologies in the context of governmentality and the emergence of culture as a strategic object of policy with the aim of citizen- and population formation and management. This argument is then linked to four contemporary "testbeds" - cultural mapping and planning, cultural statistics and indicators, cultural citizenship and identity, and research of and for cultural policy - and priorities for cultural policy where cultural studies work has been extremely enabling and productive. The article concludes with an argument, derived from the early $20^{\text {th }}$ century work of Patrick Geddes of the necessity of linking, researching, understanding and operationalising the three key elements and disciplines of Folk (anthropology), Work (economics), and Place (geography) in order to properly situate cultural policy, mapping and planning and their relationship to cultural studies and other disciplines.
\end{abstract}

Keywords: Creative industries, cultural studies, cultural policy, governmentality. 


\section{Convergence, creative industries and civil society: towards a new agenda for cultural policy and cultural studies}

Let me start with a personal experience cameo.

It's a sticky, hot, and fly-blown day in 1996. I am in a town, Geraldton, in the central coastal region of Western Australia, about an hour's flight north of the State capital of Perth. This is a coastal town with a declining rural industrial base, the stunningly beautiful Spanish mission-style Cathedral of St Xavier designed by the resident English architect priest, (Monsignor John Hawes), ${ }^{1}$ and a fairly sizeable Aboriginal population largely displaced from their traditional rural territories.

I am in Geraldton at the invitation of the local Arts Council to talk to council officers, local community and business leaders, and cultural organisations about cultural policy, cultural planning, and multimedia, and how these things might help them to build new communities, new industries, a new sense of place and identity, to provide jobs and activities for their young people - the town's biggest declared "social problem". But that is not the central point of this cameo - to talk about taking cultural studies and cultural policy "into the field" - as important as that is. The real point is to one side of - and in a relationship of actual tension with - the civic ambitions and purpose.

I walk into a place called the Yamaji Language Centre ("Yamaji" -meaning "man" or "human being" from the Wajarri language which is dominant in this area) - an organisation funded by the Australian Commonwealth government to provide skill development opportunities for the local Aboriginal population. In this centre - a little air-conditioned oasis of high technology and young people there are several high end and multimedia-capable computers. One of these is being used by a young Aboriginal boy, perhaps 14 or 15 years old. He is using Geographical Information System (GIS) software combined with multimedia authoring and visualisation packages both to discover and reconstruct the language, culture, families and social memories of his own tribal group. Using GIS he can "zoom in" on his geographical region of origin on a digital map and by clicking a few times can call up recorded fragments of a lost language, scanned pictures of elders and family members, anthropological accounts of the white "discovery" of his people, tribal and clan boundaries, secret and sacred sites and representations of his natural and cultural heritage - just the sort of thing you might see on one of the many history, anthropology, culture channels in the new TV environment. He is piecing together these various elements in a multimedia narrative to tell a story: possibly, or possibly not, with an audience in mind. The story is a rich and compelling one that it would not be possible to render in the linear written narrative of a print culture. 
The boy should be at school but he doesn't like it much. His reading and writing skills are not too good and the curriculum and teachers are apparently not helping them to get any better. But he's very good at the non-linear, interactive, spatial and often intuitive "linkage" skills that are needed for the new interactive media: layers and trellises, not "lines of communication", "transmitter-receiver" and "messages". The skills and techniques - of memory, association, gesture - of an ancient but by no means primitive oral culture are rendered into digital, multilayered and composite form.

These, after all, are precisely the skills and techniques developed in understanding the indigenous Dreaming (the foundation law or "myth" that informs Australian Aboriginal societies); in understanding the nature of Songlines - the spatiospiritual tracks of meaning and communication that secure a relationship between land and culture and define not ownership but custodianship and belonging. These are the conceptual and cognitive "mapping" skills of a non-print culture - skills that those of us trained exclusively in a print culture have forgotten or never acquired.

What is the point of this cameo? To suggest, quite simply, that there are important and enabling connections between cultural policy, cultural history and cultural studies that are currently, for epistemological, disciplinary or ideological reasons not being made where they should - or might - be. This seems to me to be disabling in the context of three opportunities for some negotiation and handshakes between a knowledge and research base on the one side and a set of both ethical and operational exigencies on the other.

These three opportunities are provided by the three "Cs" of the title - Convergence, Creative Industries, and Civil Society. Let me now take these three Cs, briefly, one by one, to sketch out some possible scenarios for negotiation and knowledge-transfer - if not yet collaboration.

The Yamaji boy was doing convergence, albeit undoubtedly without knowing or caring about it or knowing what it means. He was using the resources of three converging industry sectors - computing, communications, and content - in order to reconstruct the layers of combined narratives that, in their ensemble and compelling narrative form his family, peers and elders had never seen. Positioning himself precariously, and certainly temporarily, within what Manuel Castells calls the "global space of flows" and with all the assistance of Microsoft, Apple, IBM, and other multinational corporations in software and hardware and content, this young Aborigine was using some of the newest technologies in the world in order to find a way of locating parts of the oldest civilisation in the world in its place and for others, potentially, to witness.

At the same time, the Yamaji boy was, however informally, an "apprentice" in the creative industries if we take the definition of these as "...those activities which have their origin in individual creativity, skill and talent and which have a potential for wealth and job creation through the generation and exploitation of 
intellectual property”. (DCMS, 1998:003) He was doing creative industries with his own skills, creativity, talent and unique engagement with the content. And, while one person does not make an industry, the fact is that when this content is rendered into digital form, it has the potential for mass global circulation now through web sites, Facebook, MySpace, YouTube Twitter, etc., and the various mobile devices which facilitate the Web 2.0 generation. Depending on the content it also has the potential for commercial exploitation. There are now, for example, many videos of tracks by the blind Aboriginal singer and guitarist Geoffrey Gurrumul Yunupingu,(see http://www.gurrumul.com/) from the remote Elcho Island in Arnhem Land, which are on YouTube (www.youtube.com/gurrumul/). These provide demand stimulation for the (now very successful) commercial sale of his intellectual property on CDs and downloads and frequent commercial performances in Australia and internationally. One person but through the new media of creation, production, distribution and consumption, now an important contributor to the creative industries.

Finally, the Yamaji boy was engaged in the work of elaboration and representation of a complex potential network of forms of affiliation and communication, of reciprocity and interdependency, that can properly be called civil society both in the sense of a community of citizens and the sense of a public sphere in which the networks of relations and dependencies between citizens can be constructed, elaborated and consolidated through "stories". This is an example of what Arjun Appadurai calls "...the micronarratives of film, television, music, and other expressive forms which allow modernity to be rewritten more as vernacular globalization and less as a concession to large-scale national and international policies.” (Appadurai 1996:10). A prescient comment prior to the emergence of YouTube, MySpace, Facebook, etc. The Yamaji boy was doing civil society in this sense. Again, one person does not make civil society, but the means of exchange and communication contribute to the potential for sharing knowledge and information which are essential preconditions of a robust civil society. This was the case with coffee shops and taverns in $18^{\text {th }}$ century Europe, with the mechanised press in the $19^{\text {th }}$ century, and with analogue electronic media and the landline telephone in the $20^{\text {th }}$ century. It is even more the case with the digital interactive media and mobile telephony in the $21^{\text {st }}$ century - as witness the role of Twitter in establishing both national and transnational lines of formal and informal communication in the recent post-election conflicts in Iran. Vernacular globalisation, indeed, leading to new forms of civil society.

Arts of living, doing, and being, not just "arts": that's what culture is about.

It is now possible to briefly summarise and link these three "Cs" in a broader context of research, analysis and policy development and to outline the main directions of the argument.

Convergence of the "value chains" and the story-telling capacity of the content, telecommunications and computing industries, and digitalisation, create a dra- 
matic new context for cultural studies and cultural policy. In just a few years, the desktop or laptop computer has been transformed from a "business machine" facing inwards to a device facing outwards to millions on a "one-to-one", "one-to many", and "many to many" basis which enables and facilitates activity at every stage of the content industries value chain: from creation through production and reproduction, promotion and marketing, distribution, and point of sale and consumption. New information and communications technologies are unprecedented in their scale and extent of market penetration and consumer take up and their interactive nature is, as yet, uncharted territory but certainly, as the Yamaji boy shows, rich in potential. This offers enormous possibilities for the cultural field but also many potential threats. New research and policy development agendas are needed to respond to this context.

Creative industries: have never been so strategic or important in local, regional and national economic development. They have become a mainstream policy concern in need of an appropriate response in research and analysis. As we move, very unevenly, into a "knowledge economy" and from there to a "creative economy", the role and skill sets of creators, producers and cultural intermediaries - as creative content providers, brokers, curators, navigators, distributors, point of sale and access - become more and more important. As industries with a special relationship to local, regional, national and global identity, they have a special place on research and policy agendas. And yet we know very little about them - quantitatively or qualitatively. ${ }^{2}$ New research into both the economic potential and the social significance and impact of the creative and content industries is needed and this is especially the case in the forms and patterns of appropriation and consumption of cultural products, their transformation (investment) into forms of cultural capital, and their role in finding a place for the local in the global - the "glocal".

Civil society: culture's special and often strained relationship to policy resides in its - often silent - relationship to civil society. In both historical and contemporary terms, as we will see below, culture is about citizen-formation (and management). It is about conduct and affiliation, identity and sense of place - folk, work and place as Patrick Geddes once put it. Culture is an important capillary structure for democracy, autonomy and self-expression - and, equally, their denial. Culture is about social exclusion and inclusion. We know these things both tacitly and theoretically but there has been little work to translate these forms of knowledge into the operational policy domain and, conversely, little work to translate these "governmental" concerns back into the field of cultural studies in order to historically inform - but not control - that body of work.

How can we assist - if we want to - in this process of translation between the fields to the mutual benefit of each? Let us start with a strategic recognition of the role of "cultural technologies" from the vernacular Bible and the novel, through the almanac, the newspaper, to the laptop and the iPhone in organising sense of self, identity and lifestyle as well as larger social scale affiliations and networks. 
This is the new context and architecture for a productive "handshake" between cultural studies and cultural policy

\section{Cultural technologies: "Living, doing, thinking, and being" with culture}

It is not too difficult to see how the example of the Yamaji boy may be rich in implications for the ways in which we engage with both cultural studies and the field of cultural policy and how a focus on convergence, creative industries and civil society might assist in the work of translation from one field to the other. How can this "translation" be effected?

These concepts (and practices) are, to use an anthropological expression, good "to do with" and good "to think with". If we can agree, for example, with the American anthropologist Marshall Sahlins, that culture is a renewed strategic field in the new global environment; that "culture" has "entirely escaped academic control and been taken up by peoples all over the world in an extraordinary moment of social self-consciousness - an awareness of their own way of life as a value and above all a political right” (Sahlins 1994). Or, if we can agree with another anthropologist, Arjun Appadurai, focussing on the broader category of imagination which, he argues, "has broken out of the special expressive space of art, myth and ritual and has now become a part of the quotidian mental work of ordinary people in many societies” (Appadurai 1996: 5) then the stakes become more serious and strategic in the context of both globalisation and the transnational creative potential of the new digital media - especially mobile telephony and Web 2.0.

These stakes are about how it is possible to "re-imagine" communities both within and beyond the frameworks of the nation state and the connections that need to be made between cultural, social, environmental, economic and ethical domains in order for that to happen on a sustainable basis.

"It is the imagination", Appadurai continues,

...in its collective forms that creates ideas of neighborhood and nationhood, of moral economies and unjust rule, of higher wages and foreign labor prospects. The imagination is today a staging ground for action, and not only for escape. (Appadurai 1996:7)

Users of social networking sites will know that there is no shortage of imagination - good and bad - in the world. They will also know that they can discover these forms of imagination in places they had never witnessed - or perhaps not sought before: Iran, Sudan, Somalia, Kirghizistan, Bosnia-Herzegovina, Northern Ireland. All places of past and present conflict but also of enormous creative potential. How does this argument help in seeking grounds for dialogue between cultural studies and cultural policy? 
One part of the answer to this question lies in a resolutely practical and material approach to the cultural field and the various resources - the forms of cultural, social and other capital - that comprise it.

Another part of the answer lies in a more complex and historical understanding of the field of policy as, quite simply and according to a $15^{\text {th }}$ century definition; "[I]n reference to conduct or action generally" (Oxford English Dictionary 1979).

With that historical and lexicological reference let us now consider some historical grounding for the argument.

\section{The material culture of imagination}

To address the first part of the answer we can refer to it as the material culture of imagination. In this context we are dealing with not the representational but the ethnographic status and currency of cultural forms and technologies, especially in their more ephemeral and quotidian existence. We are concerned with the "mental tools" (outils mentaux) by which the social and the cultural are known and transacted and become "good to think with". As Roger Chartier has put it: "ways of thinking depend above all on material instruments (the techniques) or conceptual instruments (the sciences) that make them possible” (Chartier 1988:24). Geographical Information Systems software was good to think and imagine with for the Yamaji boy because it ordered its elements in spatially defined "layers" of meaning where knowledge of the land was overlain on knowledge of the culture, the heritage, the kinship relations and so on. These layers of meaning could be supported and reinforced by the (to the boy) unexceptional capacity to patch-in digitalised images from old film and newsreel and photographs and to connect them to different elements of these layers of meaning. It was not that a "way of thinking" was being produced by new material and conceptual instruments. Rather, it was that a way of thinking (and feeling, and doing) was being made representable on and in a screen - and potentially through global digital networksboth to the indigenous thinker and doer and to the non-indigenous witness.

What do these material and conceptual instruments promise for the ways in which we think and do culture in its relations with the self, identity the community and senses of place and belonging, the social and the industrial?

\section{The newspaper, for example: everyday cultural consumption and imagining}

To attempt to answer this question, let me both step back in time and take the argument further conceptually by connecting it to Benedict Anderson's proposition that the newspaper or, more precisely, the "ceremony" of its consumption, is a

"...vivid figure for the secular, historically clocked, imagined community.." which is a precondition for the use of the mental tools necessary for thinking and imagin- 
ing the nation. This ceremony of consumption transacts and secures a relationship between a mode of reading, "in the lair of the skull" and a "community in anonymity which is the hallmark of modern nations" (Anderson 1983:39-40). Conditions of emergence, conditions of production and distribution and conditions of consumption: these instances will need to be held together in a proper analysis of the newspaper form as a component of material culture and as a cultural technology of imagining. The same arguments will apply to any cultural form, whether analogue or digital in its physical manifestation and in the circumstances and rituals of and distribution consumption. Differences will be produced by the economy of usages in which the fluidity of the digital form and its interactivity will be the most important agents of transformation. "Things in their ears": from the Sony Walkman to the iPod and the iPhone, the new generation of mobile devices have dramatically transformed the rituals and circumstances, the possibilities and economy of cultural consumption, especially, though not exclusively by younger people Unlike the history and political economy of the newspaper - now so challenged by the World Wide Web that even Rupert Murdoch is not sure what to do - this is a "demand-side" calculation for which we have, as yet, neither formula nor outcome. So let us stay more safely historical for a while

There are definite conditions of emergence for the newspaper form that we may date from the late-sixteenth century coranto, a form which regularised a line of communication and correspondence between writer, printer, reader and community. These conditions are print culture (print-capitalism as Benedict Anderson calls it, the first "creative industry" dating from the fifteenth century and the invention of moveable type), the consolidation of national languages partly as a result of the new cultural technology of portable print culture and impelled by the Reformation demand for the Bible and other religious manuals in vernacular national languages, and the establishment of lines of supply and communication - a "robust value production chain" as we might now call it, through new authors, printers, publishers, distributors, booksellers and consumers. These are the necessary but not yet sufficient conditions. What makes them more sufficient is when they offer the reader a position, an identification, a place of informal knowledge, and an expectation of a commodity form, albeit ephemeral, from which things can be understood on a regularised basis.

The coranto, Anthony Smith argues, was decisive in this respect, crossing the threshold from various disaggregated forms of narrative of news events to a distinctive new genre:

The coranto was an invention of primary importance, for it attempted to provide an account of the whole world and to give its reader the feeling of comprehensive, periodical knowledge of world affairs. (Smith 1979: 11)

This is a regularity of information that will offer not only facts but also a position from which to understand them. This is part of the function of a genre: to provide 
a form of communication but also to offer instructions on how to use it. The genre is "local knowledge" but it also offers comparativism:

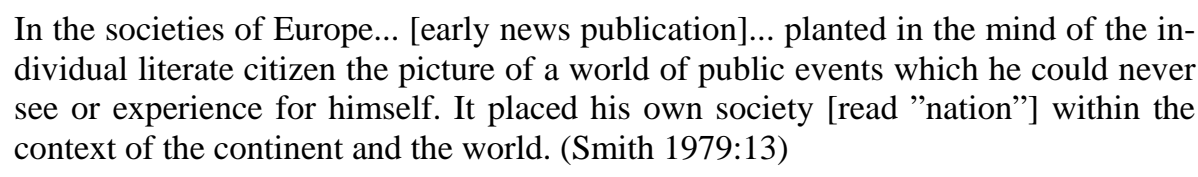
dividual literate citizen the picture of a world of public events which he could never see or experience for himself. It placed his own society [read "nation”] within the context of the continent and the world. (Smith 1979:13)

The newspaper form inaugurated a regularised mode of communication which would shift the imperatives of conduct-formation, advice on exemplary modes of governance and "manners" from the private, individualised genres of conduct manuals, Governours, books of etiquette and other devices of conscienceformation in the post-Renaissance period, into the more strategic domain of the "ordinary moral education of the people". (Roche 1987:217). In this project, the people would need to be addressed, narrated and generally talked about and imagined in relation to the context in which they could be recognisable: the nation. The slow and uneven but definite emergence and consolidation of national vernacular cultures which we can trace from cultural technologies like dictionaries, grammars, anthologies of national literature, and vernacular "pocket edition" bibles through to politico-administrative technologies like chanceries, road systems, educational apparatuses, currencies and insurance schemes offers a definite genealogy and infrastructure for an embryonic national domain. Further it is possible to know this national domain, that you are in it and part of it, by a regularity of periodical news information from the demarcated domains of both "home" and "overseas" which will have the effect of securing that comparative distinction. We have here the beginnings of a relationship between news and governmentality in its broadest sense of a strategic capillary network of communications: a protogovernmental domain.

Théophraste Renaudot was the first to combine a quite specific type of advertising and the publication of news with explicit objectives of social amelioration in $17^{\text {th }}$ century France. As Anthony Smith explains, a threshold had been crossed in which communication, well-being, and governance could easily co-exist both within a genre and within a certain social logic of the market.

\footnotetext{
It seemed to Renaudot that one of the causes of poverty in the society around him was the fact that those with goods and services to supply often failed to make contact with those who needed them...Renaudot moved.... to Paris and set up...the "Bureau d'Addresses et de Rencontre"....and provided a convenient brokerage between rich and poor. Renaudot's handbills explained that the Bureau provided the means whereby "anyone may give and receive information on all the necessities and commodities of human life and society". The aim was to reduce beggary in the streets of Paris by helping the workless to find employment, masters to find apprentices, borrowers to find lenders, the homeless to find shelter, the sick to discover medicaments. (Smith 1979: 27-28)
}

The exchange of information, regularised and institutionalised in this way, with a benign - but motivated - belief in the transparency of the social domain offers a logic of assistance and a logic of surveillance at the same time. These procedures 
of communication and exchange are directed toward the provision of those "little supplements of life" of which Michel Foucault (1979 - see below) writes.

We might characterise assistance and surveillance as the two necessary conditions of modern governance for which so many Gazettes, Couriers, Zeitungs, and Mercurys would become the exemplary genre. What combines the indigent, the working, the sick, the creditworthy, and the purchaser of commodities here is a logic of communication within demarcated domains traversed by roads and the filaments of governance increasingly replete with what we can call an "ethnie".

With the support of Cardinal de Richelieu, Renaudot assumed the direction of the officially authorised newspaper, La Gazette which continued in publication as La Gazette de France until 1917. It is in relation to precisely this period that Michel Foucault has charted the conditions of emergence of a concept of police which, he argues, "includes everything”:

...[b]ut from an extremely particular point of view. Men and things are envisioned as to their relationships: men's coexistence on a territory; their relationships as to property; what they produce; what is exchanged on the market. It also considers how they live, the diseases and accidents which can befall them. What the police sees to (surveille) is a live, active, productive man...the police must ensure "communication" among men in the broad sense of the word...As a form of rational intervention wielding political power over men, the role of the police is to supply them with a little extra strength (petits suppléments de vie). This is done by controlling "communication", i.e., the common activities of individuals (work, production, exchange, accommodation) (Foucault 1979: 248)

Of course this doesn't really include everything: it includes everything that is thought to be governable and communicable: everything that is, that can, in the words of Peter Miller and Nikolas Rose, be subject to various regimes of notation (Miller and Rose, 1990). It signals a threshold that has been crossed after which these entities and imperatives could be thought together and strategically. This is the condition of emergence of "news" as an integral rather than contingent form of communication. And there could, in fact, be no better genre to accommodate and distribute these techniques of governmentality than the emergent form of the newspaper containing news, information and - since another function of police is to survey "everything pertaining to men's happiness" (Foucault 1979:250) - diversion and amusement.

The newspaper form, assimilating some prior techniques of correspondence, literary commentary, early forms of advertising, enables new co-ordinates to be thought: the newspaper becomes good to think with in its time and in its place. As such it is a crucial device and cultural technology through which a certain sense of the national community may be inscribed. A nation can be imagined which is peopled, traversed, delimited by roads and frontiers, narratable in terms of politics, business, military affairs, commodity circulation and exchange, and, not least, petty pleasures, diversions and amusements. The origins of journalism witness a proliferation of writers traversing the native country and narrating its manners and customs, the petty pleasures and diverse amusements of its newly dis- 
covered peoples. In the UK this certainly includes the work of Defoe in the $17^{\text {th }}$ century and Samuel Johnson in the $18^{\text {th }}$ century and the outputs of new journals and magazines like The Idler, The Tatler and The Spectator in the same period. There is a generalised imperative to talk about, narrate, excoriate, the everyday manners and customs of the peoples upon whom the narrative gaze was obsessively, albeit sometimes reluctantly, fixed.

\section{The policy moment: the notation and governance of people and things in their places}

The newspaper provided the conditions of emergence and acceptability of the public figuration of ordinariness and the technique of the panorama: the possibility of representing a nation and its texture through the co-ordinates of time, space and ethnie. It is not impossible to see here a connection with that initial bringing together of disparate domains and entities into the field of government that occurred in the early eighteenth century and which Foucault has commented on by way of the Compendium of the French administrator Delamare.

Delamare lists eleven areas in which "government" can be operative. These range from religion and morals through roads and buildings to the liberal arts, labour, and the poor.

"What", Foucault asks, "...is the logic behind intervention in cultural rites, small-scale production techniques, intellectual life, and the road network?” (Foucault 1979:250). This is a logic that we can also interrogate with regard to the newspaper panorama and, indeed, the newspaper genre as a whole because here again we have a line to be traced from roads and dams to provisions to forms of religious, ethical and moral life in their diverse locations. Foucault's answer, through commentary on Delamare, takes the following form.

\footnotetext{
Delamare's answer seems a bit hesitant. Now he says, "The police sees to everything pertaining to men's happiness"; now he says, "The police sees to everything regulating "society" (social relations) carried on between men." Now again, he says that the police sees to living. This is the definition I will dwell upon....[Delamare] makes the following remarks as to the police's eleven objects. The police deals with religion, not, of course, from the point of view of dogmatic truth, but from that of the moral quality of life. In seeing to health and supplies, it deals with the preservation of life; concerning trade, factories, workers, the poor and public order, it deals with the conveniences of life. In seeing to the theatre, literature, entertainment, its object is life's pleasures. In short, life is the object of the police: the indispensable and the superfluous. (Foucault 1979:250)
}

There is a strong connection, then, between the proliferation of everyday cultural forms and the emergent logic of governance: a connection which translates cultural resources, and cultural capital into cultural technologies of person and citizen-management. This is a politics of everyday life, manners and customs - of conduct - that characterises modern forms of governance - which includes not 
just "government" but also the conditions and cultural technologies for the formation of civil society in the non-governmental sphere.

The conditions and the potential of the new cultural technologies were to be strategically recognised - and multiplied - as objects of policy in the late $18^{\text {th }}$ century and $19^{\text {th }}$ century as they led to new "disciplines of detail” in Edward Said's words (Said 1984:78).

\section{Disciplines of detail: the Abbé Grégoire and the strategic invest- ment of the cultural field}

There is nothing, of course, more discrete and everyday as a cultural form and technology than language - the "quotidian mental work of ordinary people" in Appadurai's words (see above) and at the moment of the French Revolution, punctually marking the emergence of modern cultural policy, the Abbé Grégoire (sometimes called the "Bishop of the Enlightenment" and certainly a political survivor) forms a discursive apparatus for citizen-management in which "unity of idiom is an integral part of the revolution" (Grégoire, 1988:139) and where these two unities would add up to something more substantial: unity of the nation - "the one and indivisible Republic". This is where language would be the first key mechanism for defining what is French and what is not French, what is national and what is other, what is civilised and what is barbarian: where language policy, in short, would entail the production of that body of discourse - in literature, in education, in government proclamations, in style manuals, in geographies, in newspapers, in almanacs - which defines the nation and the national. As Grégoire himself put it, "the persistence of feudal idioms and patois would only serve to perpetuate feudal ideas and affiliations” (Grégoire 1988:131).

So, Grégoire initiated one of the first mass ethno-linguistic surveys of the modern period by sending copies of a well worked-out questionnaire to local men of letters - "correspondents" - throughout the nation. He asked them to comment on the extent and circumstances of use of local patois, ${ }^{3}$ to what extent they might be operational in reproducing "old ideas and allegiances" and, in Question 24, he asks, "What would be the religious and political importance of entirely destroying this patois?" (Grégoire 1988:38)

The result of this extensive survey was a report presented by Grégoire to the Asseemblée Nationale in 1791 and entitled Report on the Necessity and the Means to Eliminate Patois and to Universalise the Usage of the French Language. This Report was received with great acclaim and, unusually, copies were sent to all administrative units - communes - in the new Republic. The central logic of the new language policy stressed that to

...eliminate all prejudices, to develop all truths, all talents, all virtues, to meld all citizens into the national mass, to simplify the mechanism and to facilitate the working of the political machine, there must be identity of language. The time will cer- 
tainly come when there will be other necessary reforms to be undertaken in dress, in manners and in usages.(Grégoire 1988: 138)

Millions of almanacs, brochures, posters and manuals - "not big books but a mass of patriotic pamphlets" (Grégoire 1988:140) - were sent out into the countryside in order, as Grégoire put it, to provide the "soft voice of persuasion" (Grégoire 1988:132) in the form of simple ideas which will appeal to the "slow-witted" by offering commentary on politics and the arts, hints on household management and husbandry and, above all, provide a uniform system of classification and naming in money, weights and measures, fashions and customs.

This is an example of the role of the words, gestures and practices and the material cultural technologies of everyday life in constituting what counts as culture and the national - what is subject to policy formulation, what is governable from the point of view of both governments and populations. Grégoire was probably the first legislator to take seriously - and to elaborate a policy framework for the management of populations through detailed attention to certain sets of customs, manners, usages, classifications. This is culture as the strategic terrain of population, citizen and self-formation. This ethnographic imperative is the impulsion to recognize, chart and organise the customs, manners, habits and activities of whole populations. It is a movement that we witness everywhere in Europe from the end of the 18th century in novels, medical treatises, new forms of entertainment, antiquarian interest in folk customs, folk tales and etymology of the national language and the slow emergence of new disciplines resembling sociology and anthropology.

Culture here means habitus, a "system of acquired schema functioning in the practical state as categories of perception, appreciation and classification which are simultaneously principles for action.” (Bourdieu 1987:24). More simply we can say "habit-forming forces". The origins of popular education, museums, concerns with the health and leisure activities of populations, the origins of sewage maintenance, street lighting and community arts. Cultural policy and politics as, in de Certeau's words, "a more or less coherent body of objectives, means and actions aiming to modify behaviours according to explicit principles or criteria” (de Certeau 1980:191 - my emphasis).

In his characteristic concerns with questions of communication and language, with public monuments and museums, with the icons and symbols of government (design of bank notes and the Seals of the Republic, place and street names, etc), with the rituals and gestures of popular association (hand-shakes, modes of address, liberty trees, Festivals of the Republic, etc.,). Grégoire stands as an exemplary case study of the ways in which, in the modern period, the concerns of government came together with those of "culture". Robespierre, his boss for a while, was also very keen on festivals as unifying national events.

Grégoire's concept of culture is broad, strategic, and, we might say, literally "street-wise". In his Report on The system of topographical denomination for 
places, streets, quays, etc, in all the Communes of the Republic, he develops his argument in the following terms:

I submit to you a systematic plan which will establish everywhere names and emblems which are capable of providing useful exercise for the mind, of acting on the heart and of encouraging and maintaining patriotism. This will have the further advantage of facilitating postal services, the movements of commerce, the researches of travellers, the exercise of police and the levying of imposts. (Grégoire, $1977 \mathrm{Vol}$ IV:160)

The logic of these actions of "detail" is explained:

The people is all, and everything must be done for the people. It is above all in certain arrangements of detail in which government manifests its paternal solicitude for the people and its benevolence towards strangers. (Grégoire 1977, Vol IV: 160 emphasis added).

This emphasis on "arrangements of detail” brings us to the core of the relationship between cultural studies and cultural policy. As Edward Said has argued:

The range of specialised disciplines that arose in the nineteenth century were disciplines of detail by which the human subject was first collapsed into swarming detail, then accumulated and assimilated by sciences designed to make the detail functional as well as docile. From that evolved a diffuse administrative apparatus for maintaining order and opportunities for study. (Said 1984: 220-221)

\section{Opportunities for research and "testbeds" for policy development}

The argument so far has attempted, through some historical reconstruction, to position cultural policy as a legitimate object of study and analysis with the field of cultural and communications studies. That is to say, from the point of view of cultural policy, that the organization, embedding and management of the "cultural resource base" was - and remains - of great import to broader strategic and governmental agendas. This is not, as in many forms of analysis in cultural studies, principally for reasons of "ideology" understood in a cognitive/representational framework and thereby susceptible to various forms of hermeneutic or semiotic analysis or deconstruction. Rather, it is a matter of regular, practical usage and orientation: le sens pratique in Bourdieu's formulation.

The concern with policy as a focus not only on "government and bureaucracy" but also as a methodological emphasis on questions of conduct - lignes de conduite or "lines of conduct" in a French definition of policy matching that earlier English definition recorded in thee OED referred to above - becomes clearer in this context. It does not signal, in other words, simply a concession to or complicity with "government" in traditional terms but, rather, argues for a systematic inclusion and recognition of the necessarily "governmental" role of the recognition and management of cultural resources, in historical terms, since at least the mideighteenth century as "populations" and "citizens" became new objects of political calculation and strategic management. 
This is another way of saying that the relationship between continuing concerns with cultural history and theory and the operational focus on contemporary policy is not a contingent or intrinsically antagonistic one. This relationship is governed by a concern with the precise nature of both the theoretical and the policy object: culture. "Cultural Policy Studies” could be translated, in other words, into "Studies in the Relations of Governmentality and Culture". There is, in other words, a close connection between attention to the "technologies" detail and minutiae of culture - culture as resources, culture as techniques, uses, tactics and strategies and the ways in which we operate in both "pure" and "applied" research. The concern is not simply with what culture represents but with what it actually does in both exceptional and everyday terms. This is not culture as consciousness or ideology or text to be deciphered by decoding the rules, structures and conventions but culture as practical orientation (sens pratique) using the resources, especially the material culture, available to think and do and be. This is, clearly. much more of an "anthropological" than an aesthetic/representational approach to the analysis and management of culture but it is also one which enables a far more productive relationship between "pure" research and "applied" research than the terms will currently allow.

There are a number of areas of work in cultural policy, in which the dichotomy of "pure" and "applied" has been of no use at all but where the relationship between them has been enormously productive. These are in the "testbeds" of cultural mapping and planning, culture, citizenship and identity, cultural indicators, and research of and for policy, all of which have prominent and increasing profiles in national and global policy settings. Let us briefly consider and unpack these testbeds to identify the potential for convergence of the interests and skills of both cultural policy and cultural studies.

\section{Testbed 1: Cultural Mapping and Planning.}

This is work being undertaken, especially in Australia, Canada, Columbia and the UK, informed by various conceptual frameworks and methodologies, both quantitative and qualitative, in collaborative research, policy analysis and development in urban, regional and community contexts. It is targeted at providing the necessary frameworks and tools for the "mapping" and planning of cultural resources. These resources normally include, and frequently start from, "the arts" as traditionally defined and specified in government funding, service, and statistical frameworks. But the work also includes, in qualitative terms, a necessary conceptual broadening of the meaning of culture and of what counts as culture to different sectors of the target population. This often involves ethnographically-oriented survey and consultation work as well as the statistical counting of the number of people, businesses and organisations in the defined cultural sector, patterns of growth and consumption over a defined period. 
The move from an aesthetic to an anthropological definition of culture - frequently the product of prior survey work on "what counts for you?" - and its implications for resource management, funding, service delivery and general policy purview and applicability is crucial here. Shopping centres, churches and temples are often much more vibrant and effective "cultural centres" than those officially blessed with that name but they are not normally recognised in extant policy frameworks. Streets and buildings are cultural resources as are the forms of intangible cultural heritage in festivals and local traditions. Again, these resources are frequently not recognised. In urban and regional planning frameworks where the question of culture is usually reduced to issues of embellishment and beautification - an aesthetic definition - rather than the more effective operational and anthropological definition of how people use, relate to, celebrate or desecrate their living environments. The process of "cultural mapping” which needs to be integrated with broader processes of planning provides ways, both qualitative and quantitative, of, on the one hand, conceptually recasting the boundaries of culture and, on the other hand, of forcing policy and planning frameworks to redefine their own operational and resource allocation parameters. You have to "notate before policy" as Grégoire might have put it or "survey before plan" in Patrick Geddes' expression well known to planners but rarely practised by them (see "Coda" below)

This is resolutely workaday and technical work. It involves consultation and negotiation with local government officials, librarians, architects, planners, traffic engineers, community organisations, people in the streets and at the end of telephone lines in order to recognise, map and strategically plan and manage cultural resources. You cannot easily do that if you are guided by an aesthetic approach to culture. You cannot do it either, in my view, if you are not familiar with some of the best theoretical work in the area of urban history, cultural and otherwise. The work of Mike Davis, Richard Sennett, Ed Soja, Sharon Zukin, Anthony Vidler to name only the most prominent, has been invaluable in identifying the limitations and implications of some forms of "cultural development" in the urban context (artists being the "stormtroopers of gentrification", for example or the role of the boulevard as simultaneously a cultural, political and commercial space in modern cities). The extensive body of work in cultural studies on urban cultures, subcultures, minority ethnic cultures, indigenous cultures, etc., has been valuable when "translated" into these policy contexts. That is not to say that, when doing operational policy work, one carries around these weighty tomes on site to point or refer to for guidance. It is simply that this body of work in its concentration on the history of the "little [and grand] tactics of the habitat" (Foucault) provides an invaluable basis for understanding, in the contemporary context, the possible implications of policy and planning decisions for the communities large and small, urban and rural, national and transnational in which one is currently operating. 


\section{Testbed 2: Citizenship and Cultural Identity.}

This is the research agenda in cultural policy that covers the work, pure and applied, in explicit equity areas such as gender, interculturalism and cultural diversity, marginalised young and older people, and in relation to indigenous cultures and social exclusion. It also covers the more general investigations into the relationship between citizenship and cultural resources in areas such as heritage, education, film and media policy and intellectual property. This is a research schedule which is concerned explicitly or implicitly with the role of cultural resources in the construction and reconstruction of identity, or, more technically and theoretically, with "techniques of the self" and, further, "techniques of community and population" formation and management. It is not - and this is important - a celebratory agenda. From a "governmental" point of view, it is important to recognise that "cultural identity" is not by any means a benign repository of human values and aspirations. What has happened in the Balkans, most acutely in Bosnia- Herzegovina, is a matter of cultural identity and cultural policy and in that context is clearly and acutely a strategic governmental issue ${ }^{4}$. Clearly, therefore, any concern with cultural identity has to negotiate its way through a series of complex questions and issues such as: identity on whose terms and to what ends and in what balance between rights and obligations? Is the Mostar bridge destroyed by Serbs in Bosnia a cultural object? It was to the Serbs and the Croats. Were the mosques in Sarajevo, also destroyed by the Serbs, cultural objects? They certainly were to the Bosniaks and the Serbs. Were the Eastern Orthodox churches in the Serbian regions destroyed by the Roman Catholic Croats cultural objects? They certainly were to the Serbs and to the Croats. These scenarios of lethal conflict over cultural resources - from physical infrastructure to ways of dressing and lifestyle orientations - have been repeated in many more countries - Afghanistan, India, Sudan, Somalia. This is why the "governmental" concept of citizenship rather than the more free-wheeling (and often aesthetically determined) concepts of "subjectivity" and identity shapes the agenda in cultural policy. But, importantly, it draws on concepts of both identity and subjectivity which have been more central to cultural studies especially in the context of ethnicity and ethnie.

This is the "constraint" side of the equation. On the "potential" side it is clear that a lot of work needs to be done in this area to account for and redress, for example, the inadequacy of current cultural policy frameworks and resource allocation mechanisms, to recognise, let alone address, the needs and expectations, of women, ethnic and diasporic communities, indigenous communities and youth in strategies for the development of the creative industries. Again, this is not merely a question of giving more resources to identified equity groups. It is also a conceptual issue of recognising and managing the resources that count as cultural to those groups - another crucial contribution of cultural studies to policy from Stuart Hall, Dick Hebdige and Paul Gilroy onwards. An aesthetically determined arts framework, to be found in most so-called cultural funding agencies, for example, 
is not well-positioned to address the needs of non-European and indigenous communities who recognise neither the European concept of art, nor the aesthetic hierarchy of discrimination and evaluation which govern resource allocation and policy agendas in that area. New conceptual understandings and definitions of the cultural field are necessary to inform policy. This is a crucial meeting point for cultural studies and cultural policy.

\section{Testbed 3: Cultural Indicators and Impacts.}

This last point applies especially to cultural indicators and impacts, quantitative and qualitative, which are now much in demand by all levels of government and cultural organisations from local to global levels. This is a research agenda which is ostensibly more "quantitative" in response to the sheer dearth of appropriate cultural statistics and indicators and conceptual frameworks for defining and understanding "impacts". In fact, while based on statistical work and various forms of body counting, it is the blindingly obvious qualitative outputs which are probably more important. In other words, before you can "count” culture you have to know what counts as culture for the stakeholders and communities involved. The facts on who is visiting our museums and art galleries - and who is not visiting them and why - what the major patterns and forms of cultural consumption and participation are by ethnicity, gender, age and location provide some fascinating government and industry-relevant data and show clearly, furthermore, the need for sustained research (and research funding) in this area. Apart from any pure research objectives it is hard not to notice the significant mismatch between current policy frameworks and the actual patterns of cultural activity. As Tony Bennett has argued:

...[t]he causes of inequality of cultural opportunity are so deeply rooted in the fabric of [...] social life they cannot be simply conjured out of existence by the mere wave of a policy wand. Yet, if the problem is to be tackled effectively, it must be properly defined; and if we are to find out where, when and how progress is made, many aspects of the operations of our public cultural institutions need to be more precisely, more regularly and more pointedly measured than is at present the case. (Bennett 1994:23)

Like social statistics and indicators in the nineteenth century statistics as part of the "art of government" as Grégoire put it, cultural statistics and indicators in the 20th and 21st centuries provide not simply a "picture” of activity but also a set of indicators and a "system of notation", the aim of which is, indeed, "governmental". And while government can always be construed as on the side of the "coercive", we would be in no position to stake our own "governmental” claims - and claims to governance - if we were not in possession of these indicators and, especially, the knowledge base that informs them. 


\section{Research of or research for policy?}

This brings us to the testbed of the relationship between research of cultural policy and research for cultural policy: this is an important nexus for cultural policy and cultural studies. The concern, in various publications and debates is that of the equilibrium which is established between non-commissioned (grant-funded or independent) and commissioned research funded by government, intergovernmental or commercial agencies. The former would normally be deemed to be the area of research of policy and the latter the area of research for policy.

But the distinction is a difficult one to maintain for a number of reasons. Any research of policy has the potential, since it is in the public domain, of being research for policy. The outputs of many forms of "pure" research by academic writers such as Arjun Appadurai, Homi Bhabha, James Clifford, Amartya Sen, Michel de Certeau, Tony Bennett, Pierre Bourdieu, Marshall Sahlins and Stuart Hall, to name but a few key names in the cultural field, are increasingly frequently used in cultural policy-related publications generated by UNESCO, The OECD, The European Union, The Council of Europe, The World Bank, national government enquiries, etc. Similarly, it is difficult to undertake, for example, the history of museums, of tourism or of urban cultures and do research of policy without it being taken up as research for policy either explicitly or implicitly.

Following this circle round it is the case, of course, that the findings of research for policy - the absence, for example, of a recognition of or funding framework for "traditional" or "folkloric" cultural forms which are not European in origin or indigenous cultures - can productively feed back - or, better, forward - into research of policy. The trick is to make sure that this wheel keeps turning - of, for, of, for, of, for - and does not stop at any one point. That cultural studies, cultural, economic and social geography, cultural and social anthropology, development economics provide crucial resources and knowledge to inform and enable new policy settings and priorities.

This wheel not only needs to keep turning but needs to be considerably speeded up. The connections and feedback mechanisms between research of and research for cultural policy seem to me to be increasingly important in the context of the new needs of mass education systems in the post-industrial West and the needs for consolidating the relationship between culture and development in the South in content development, capacity and institution building. We know so little about the current configurations of cultural behaviour and capacity that we cannot hope, without a significant boost in research effort to know not only about the creative industries about which we have been ignorant - at least in our policy frameworks - for so long, but also about the implications and effects of communications and information technologies which are steadily and radically transforming the cultural landscape and the civil society which is constructed upon it and with it. In the context of an explicit commitment to cultural development, cultural diversity, and the creative industries at the international level and the proliferation of cul- 
tural policies and investments at other levels, we would be mistaken to construe the relations between culture and government as those of antagonism or bad faith. If the concept of governmentality means anything in this context, then it means recognising our implication, with the processes and cultural technologies that shape and form our identities and capacities as citizens and populations and taking that position and not some Archimedean position of externality as the necessary starting point for negotiation.

\section{Coda: Place, Work and Folk}

I started with a policy-related thematic triad to identify priority focus areas for cultural studies and cultural policy - Convergence, Creative Industries and Civil Society - and I will conclude with another, more methodologically oriented triad - Place, Work and Folk - in order to wrap up the argument. In this I refer to the eccentric - but suggestive and enabling - work of Patrick Geddes, often described as the "father of town and country planning" but much more than that in the early twentieth century.

Geddes' attempts at the convergence of the disciplines of geography (place), economics (work) and anthropology (folk) through his adaptations of Frédéric Le Play's work on the European family and his own work in the Edinburgh Outlook Tower, provides a more useful basis for both analysing and managing the contemporary imperatives of governance in rapidly transforming cultural domains. These imperatives include the understanding of lifestyles and cultural patterns; the nature of economic units in post-industrial economies, and the need for strategic and integrated approaches to cultural research, policy development and planning. And, most importantly, ways of thinking these domains together and developing appropriate policy and planning settings accordingly: joined up thinking for joined up government.

Let us accept the dispersed nature of political power in democratic polities operating "through a multitude of agencies and techniques" (Miller and Rose 1990: 1), many of which are only "loosely associated" with formal state institutions. Cultural institutions such as libraries, museums, galleries, public broadcasting and communications systems and cultural programmes like city animation, public art, civic leisure and recreation and even cultural/creative industry" initiatives, fit neatly into this definition, operating, as they do, at "arms length" from formal governmental processes.

Let us also accept that government needs to pay particular attention to indirect mechanisms for "aligning economic, social and personal conduct with sociopolitical objectives" (Miller and Rose 1990:2). This is directly germane to concerns in cultural policy and planning given the special relationship between culture, forms of conduct, behavioural dispositions and value systems - a relationship which finds its privileged locale in the concept of citizenship. Cultural insti- 
tutions and practices have a special place in shaping and modifying forms of social and personal conduct guided by principles of "civilisation", "cultivation" and the development of particular cultural dispositions and attributes. This is a special domain which emerges, clumsily and unfinished, from Geddes' work and which is now finding its way back onto cultural planning agendas and in areas such as cultural industry development, cultural tourism, "placemaking” initiatives, a generalised concern with urban "lifestyles" and a broadening of the agenda for the assessment of "quality of life" and, more recently. "wellbeing" as a priority and imperative for government, especially at the local level.

Geddes positions what he calls "culture-policy" in a profound linkage with the formation and maintenance of citizens and populations - civics and the production of the conditions for "actual citizenship" - and also as an integral component of the larger planning process linking the nodes and valencies of folk, work and place. This is a distinctive and productive move subsequently ignored by planners, geographers, and economists alike but now finding new forms of convergence in a post-industrial, globalised context. There were many advocates of citizenship, including the prominent economist Alfred Marshall, but few who placed the concept and the ideal in the context of policy and planning in specifically urban and regional contexts and even fewer who transacted this relationship in the domain of culture.

In Geddes, then, we can identify an embryonic form of more comprehensive notation for the strategic role of the concept of the "civic person" or citizen, understood as requiring new forms and a new logic of governance which, through forms of supervision, calculation and administration, would be concerned more comprehensively - and embracing these areas as domains of policy - with the management of human relations, environmental, infrastructural, economic and socio-cultural resources.

It is clear that in the nineteenth century, the shift in the logic of government required more detailed and sustained attention to the production and development of new knowledges and notations in order to render "aspects of existence thinkable and calculable" (Miller and Rose 1990:5), prior to becoming objects of a dispersed regulatory and policy apparatus. Thus, initially, the concern with the "manners and customs" of the people which was evident in the development of disciplinary knowledges such as anthropology and ethnography - including "folklore" - renders thinkable and calculable domains of human existence and activity which had not previously been within the purview of government and, therefore not, properly speaking, "objects of policy".

The "municipalisation" of forms of government in the larger urban areas in the second half of the nineteenth century led to the development of more sophisticated forms of management focussed on the person-environment relationship, manifest in French "urbanism", in the eugenics-civics nexus in which Geddes and his colleagues initially worked, and, most importantly, in the development of municipal 
structures of government which articulated economic and social well-being, leisure and recreation, cultural services and public health, and social infrastructure relating to waste disposal and transport management for the first time.

This is the context in which we should approach the question of "policy": "...the very existence of a field of concerns termed 'policy' should itself be treated as something to be explained" (Miller and Rose 1990:3). Thus, rather than treating policy as something which is simply "there" and fully fledged as a discipline of study or field of knowledge and action, there is a need to recognise its historical novelty as itself produced by the new logic of governmentality. This is especially - and still - the case with that object most resistant to policy, planning and government: culture.

The concern with "policy" leads to new forms of intellectual labour and to new procedures of "documentation, computation and evaluation" (Miller and Rose 1990:6). Among these we should certainly count the development of social statistics in the nineteenth century - and the renewed attention to the accumulation of cultural statistics, indicators and impacts today. We should also count among these new systems of documentation and classification the techniques and procedures developed by institutions in the cultural field such as museological systems of classification, library-based classification systems and the demarcation of the "art forms" which became the subject of national government intervention, essentially through deficit funding mechanisms, in which the role of John Maynard Keynes in the development of the "Arts Council" model was crucial.

Geddes' work directly engages with the governance of the "autonomous self" in the form of constituting the citizen as a mechanism for establishing a contract between person and environment, individual and society: in habitus. The citizen, with rights and corresponding duties was the linchpin for the development and, most importantly, the articulation of programs in child welfare, health and mental hygiene, education and social insurance. Predating these developments, this nexus is there in Geddes' work too. As Helen Meller argues,

What was needed, Geddes suggested...was to create a new way of thinking centred on the production and development, not of goods, but of people. (Meller 1990:13)

These words suggest that we should, perhaps, be properly concerned, in the understanding of culture and governance with the management of the relationship between folk, work, and place.

Where does this lead in terms of policy and planning and, indeed, politics? To a more complex, more "object of policy" oriented, and less "passionate" engagement with the disciplines of detail and systems of notation which constitute the cultural field. In the cultural field, this means attention to a less totalising and transcendent and more "technical" engagement with cultural resources (and their uses) rather than culture as principally a field of expression and identity. This will lead to a logic of policy and politics, as Jacques Donzelot has put it, where 
...the progressive substitution of the concept of participation by the concept of implication is the most significant symptom. We have seen that the concept of participation, especially in the 1970s, led to a problematic of power, and of power considered as something "to have". As a consequence, the various associations found themselves condemned claiming "always more" local power...The shift from a logic of methodically programmed centralised subvention to a contractually agreed project logic entails the necessity of an association for action and no longer a struggle for power (Donzelot 1991: 34)

That is to say, that if the concept (and practice) of citizenship is to have any resonance, the real cultural complexities of the relationship between folk, work and place, will need to be engaged with on terms which recognise the "ecological" complexity of socio-cultural relations and governance

These are complexities produced by culture-as-governance which have only been partially recognised and which require the development of multidisciplinary "key competencies" and "policy communities" in the ways that Geddes suggested, embryonically, in the following areas:

- In community anthropology and ethnology, including the patterns and rituals of the use of space, objects, narratives by differentiated populations and sub-cultures. Both statistical and social survey methods, quantitative and qualitative, can provide significant indicators about the "uses of culture and community" which are crucial to the constitution of appropriate forms of governance for both government agencies and stakeholders and client groups.

- The measurement and assessment of "quality of life" in responsive and comprehensive terms. Current frameworks for quality of life evaluation tend to be based on generic and objective social and economic indicators which could apply to the nation as a whole, to a region or to a small town. This has been greatly advanced recently by the adoption of quality of life indicators from Local Agenda 21 by national governments and, especially Local Agenda 21 for Culture adopted in 2004 in an initiative led by the cities of Barcelona and Porto Alegre (see:

http://www.bcn.es/cultura/agenda21cultura/index_en.htm).

For governance to develop its own system of notation and therefore a responsive particularity, there is a real need for a new suite of specifically cultural benchmarks, objective (how many museums) and perceptual (do we want to go, feel comfortable and included there?) which can be assessed by stakeholders and act as publicly-owned performance indicators for government programmes.

- The "stewardship" and "custodianship" of resources - environmental, social, economic, infrastructural, cultural. Ownership, the possession or control of resources and power, is not, as Donzelot argues above, the central issue. What is most crucial in developing the 
relationship between rights and responsibilities through the concept of citizenship is the development of programme and project logics, in the cultural field, for the management of resources. A system of notation, representation and intervention which could, for example, mark out a "sense of place" which is not purely celebratory and affirmative through now traditional means such as festivals and public art schemes, but also "governmental" in its ambitions to develop a "strategic plan" for that place including sustainable employment initiatives (ie. Folk-Work-Place) would move significantly beyond the enclave and sectoral logics currently influencing research, analysis and policy in the cultural field.. (see Mercer: 1997 for a fuller elaboration of the important ce of Geddes in this context)

For Geddes to have been able to postulate these connections between planning, civic virtues and interests, citizen-formation, the management of public behaviour and social well-being, and to propose the institutions and cultural technologies through which these ends could be achieved, a good deal had to have happened in the nineteenth and early twentieth centuries to have made these connections and logics thinkable in strategic terms. There is no reason why this broader logic of urban and community government cannot be re-positioned in pedagogical, political and policy terms to make it re-thinkable in and for the $21^{\text {st }}$ century.

Understanding the interactions of Place, Work and Folk in this apparently simple but conceptually rich - and necessarily interdisciplinary - formulation, would enable us to think and act in more productive ways about the interests, needs and capacities of that young Aboriginal boy and many hundreds of millions precariously positioned, like him, in urban and rural, developed and less developed contexts throughout the world, in relation to cultural capital and the cultural field.

For this to happen, however, there needs to be an effective recognition in $\mathrm{re}^{5}$ search, policy and teaching frameworks, of the necessity of finding a new articulation between culture as a "governmental" prerogative and the competencies formed and distributed in new cultural field.

Colin Mercer has previously been Director of the Australian Institute for Cultural Policy Studies and Associate Professor in Cultural Policy and History at Griffith University. Between 1999 and 2003 he was Professor of Cultural Policy and Director of the Cultural Policy and Planning Research Unit at The Nottingham Trent University. He has now specialised in freelance strategic research and development for the cultural sector, focusing on areas such as creative industries, cultural mapping, cultural planning, cultural indicators and building the knowledge base for cultural policy. 


\section{Notes}

1 One of 20 churches that he designed, in his 15 years there, in smaller rural communities in Western Australia from 1915 to 1930.

2 Though, since the invention of the concept of 'creative industries' and it's gradual positioning within mainstream policy by the UK Blair Government in 1997 this agenda, in research and policy as been greatly accelerated by new work and policy settings in both individual countries - Australia, Brazil, Canada, Columbia - and by international organisation such as the EU, International Labour Organisation (ILO), United Nations Conference on Trade and Development (UNCTAD), UNESCO, United Nations Industrial Development Organisation (UNIDO) and NGOs such as the International Network for Cultural Diversity (INCD).

3 Not just dialects or accents but grammatically and semantically different languages like Breton, Gaelic or Provençale. These are - or can be - as different from modern French as Cornish, Irish and Scottish Gaelics, Welsor Welsh are from modern English.

4 Bosnia and Herzegovina is the recent beneficiary of \$US 8 million allocation from the Spanish Government through the Millennium Development Goals programme for a 5 year project Improving Cultural Understanding in Bosnia and Herzegovina - which will require the development of a new cultural policy framework, new legal instruments for culture and new linkages between cultural and education policies. The programme is managed and overseen by the United Nations Development Program (UNDP).

\section{References}

Anderson, Benedict (1983): Imagined Communities: Reflections on the Origins and Spread of Nationalism, London: Verso.

Appadurai, Arjun (1996): Modernity at Large: Cultural Dimensions of Globalization, London: University of Minnesota Press.

Bennett, Tony (1994): ”Research and Cultural Development”, M. Breen (ed), Enhancing Cultural Value: Narrowcasting, Community Media and Cultural Development, CIRCIT: Melbourne.

Bourdieu, Pierre (1987): Choses dites, Paris: Editions de Minuit.

DCMS (1998): (Department for Culture, Media and Sport - UK), Creative Industries Mapping Document, London: DCMS.

de Certeau, Michel (1980): La culture au pluriel, Paris: Christian Bourgois.

Donzelot, Jacques (1991) (ed): Face à l'exclusion: le modèle francais, Paris: Editions Esprit.

Foucault, Michel (1979): "Omnes et singulatim: towards a critique of political reason”, The Tanner Lectures on Human Values, Stanford: Stanford University Press.

Grégoire, L'Abbé (1977) (ed.): Albert Soboul Oeuvres Complètes de l'abbé Grégoire, (14 vols), Paris: Editions d'Histoire Sociale.

Grégoire, L'Abbé (1988) (ed.): Frank Paul Bowman, L'abbé Grégoire: éveque de lumières, Paris: Editions France-Empire.

Meller, Helen (1979) (ed.): The Ideal City, Leicester, Leicester University Press

- (1990) Patrick Geddes: Social Evolutionist and City Planner, London, Routledge.

Mercer, Colin (1997): "Geographies for the present: Patrick Geddes, urban planning and the human sciences”, Economy and Society, 26(2), 211-232

Miller, Peter and Nikolas Rose (1990): "Governing Economic Life”, Economy and Society, 19(1), $1-29$.

Oxford English Dictionary (1979): Oxford: Oxford University Press.

Roche, Daniel (1987): The People of Paris: An Essay in Popular Culture in the Eighteenth Century, Leamington Spa: Berg.

Sahlins, Marshall (1994): ”A Brief Cultural History of Culture”, Unpublished paper prepared for the UNESCO World Commission on Culture and Development. 
Said, Edward (1984): The World, The Text, and the Critic, London: Faber \& Faber.

Smith, Anthony (1979): The Newspaper: an International History, London: Thames and Hudson. 